\title{
Hydropedology: Synergistic integration of pedology and hydrology
}

\author{
Henry Lin, ${ }^{1}$ Johan Bouma, ${ }^{2}$ Yakov Pachepsky, ${ }^{3}$ Andrew Western, ${ }^{4}$ James Thompson, ${ }^{5}$ \\ Rien van Genuchten, ${ }^{6}$ Hans-Jörg Vogel, ${ }^{7}$ and Allan Lilly ${ }^{8}$
}

Received 6 March 2005; revised 26 December 2005; accepted 9 February 2006; published 9 May 2006.

[1] This paper presents a vision that advocates hydropedology as an advantageous integration of pedology and hydrology for studying the intimate relationships between soil, landscape, and hydrology. Landscape water flux is suggested as a unifying precept for hydropedology, through which pedologic and hydrologic expertise can be better integrated. Landscape water flux here encompasses the source, storage, flux, pathway, residence time, availability, and spatiotemporal distribution of water in the root and deep vadose zones within the landscape. After illustrating multiple knowledge gaps that can be addressed by the synergistic integration of pedology and hydrology, we suggest five scientific hypotheses that are critical to advancing hydropedology and enhancing the prediction of landscape water flux. We then present interlinked strategies for achieving the stated vision. It is our hope that by working together, hydrologists and pedologists, along with scientists in related disciplines, can better guide data acquisition, knowledge integration, and model-based prediction so as to advance the hydrologic sciences in the next decade and beyond.

Citation: Lin, H., J. Bouma, Y. Pachepsky, A. Western, J. Thompson, R. van Genuchten, H.-J. Vogel, and A. Lilly (2006), Hydropedology: Synergistic integration of pedology and hydrology, Water Resour. Res., 42, W05301, doi:10.1029/2005WR004085.

\section{Introduction}

[2] It is well recognized that progress in science depends increasingly on an advanced understanding of the interrelationships among different disciplines and their components [American Association for the Advancement of Science Council, 2001]. An interdisciplinary systems approach is a proven vehicle for addressing a wide array of environmental, ecological, agricultural, geological, and natural resource issues of societal importance. Over the past few decades, there has been a growing interest in the adoption of a landscape perspective when examining cross-disciplinary issues such as nonpoint source pollution, watershed management, integrated agricultural systems, precision farming, sustainable land use, and ecosystem restoration and preservation. With a landscape perspective comes the need to address inherent variability in the field and to transfer knowledge and data across scales from the laboratory or small plot to the larger field and watershed scales. It also raises the need for field experimental designs

\footnotetext{
${ }^{1}$ Department of Crop and Soil Sciences, Pennsylvania State University, University Park, Pennsylvania, USA.

${ }^{2}$ Laboratory of Soil Science and Geology, Wageningen University, Wageningen, Netherlands.

${ }^{3}$ Environmental Microbial Safety Laboratory, ARS, USDA, Beltsville, Maryland, USA.

${ }^{4}$ Department of Civil and Environmental Engineering, University of Melbourne, Parkville, Victoria, Australia.

${ }^{5}$ Division of Plant and Soil Sciences, West Virginia University, Morgantown, West Virginia, USA.

${ }^{6}$ George E. Brown Jr. Salinity Laboratory, ARS, USDA, Riverside, California, USA.

${ }^{7}$ Center for Environmental Research, Halle, Germany.

${ }^{8}$ Macaulay Land Use Research Institute, Craigiebuckler, UK.

Copyright 2006 by the American Geophysical Union. 0043-1397/06/2005WR004085
}

and models to take into account the spatial scale triplet (spacing, support, and extent) and the temporal scale triplet (sampling frequency, smoothing or averaging interval, and length of record) [Blöschl and Grayson, 2000]. The changing factors that control abiotic and biotic processes in the landscape continuum should also be taken into account for effective modeling and reliable prediction.

[3] Pedology and hydrology are scientific disciplines inherently associated with the landscape perspective. Pedology is a branch of soil science that integrates and quantifies the formation, distribution, morphology, and classification of soils as natural or anthropogenically modified landscape entities [Wilding, 2000; Buol et al., 2001], while hydrology deals with the occurrence, distribution, circulation, and properties of water on and beneath the Earth's surface and its relationship with the living and material components of the environment [National Research Council (NRC), 1991; Hornberger et al., 1998]. Soil-water interactions across multiple scales control much of soil development and resulting spatial variability studied by pedologists. These interactions also control water quantity and quality in surface and groundwater systems studied by hydrologists. Combining pedologic and hydrologic expertise can be particularly powerful in addressing complex environmental issues and policies [European Confederation of Soil Science Societies, 2004; Bouma, 2006]. Indeed, interactions between soil and water create the fundamental interface between the biotic and abiotic and thus function as a critical determinant of the state of the Earth system. Traditional solutions and approaches to measuring, modeling, and predicting water flux in soils and over landscapes (including the transport of chemicals and energy by flowing water) have long been plagued by fragmented discipline-limited efforts and inadequate perceptions among pedologists and hydrologists of the expertise available from each other. For 
example, the following limitations need to be overcome in order to ally pedology and hydrology [Lin et al., 2005a].

[4] 1. To many hydrologists, pedologists use unfamiliar, highly structured terminology to describe field soils and make empirical statements about soil functions based on field observations that are not necessarily supported by measurements. On the other hand, pedologists challenge the often simplistic representation of field soils that hydrologists frequently assume in their models;

[5] 2. Pedology has its roots in soil surveys that consider soil-landscape relationships and soil structure. These two aspects are critical for surface and unsaturated zone hydrology in order to improve quantitative characterization of flow regimes in the field. However, pedologic knowledge is often conveyed as qualitative or semiquantitative statements. Pedologists thus can benefit from flow theories in hydrology when transforming qualitative descriptions into quantitative expressions that are increasingly in demand.

[6] Many knowledge gaps can be addressed by the synergistic integration of pedology and hydrology. The following five aspects exemplify the point.

[7] 1. Prediction of preferential flow dynamics and pathways at different scales, their interface with the soil matrix, their residence times, and their significance in different soils and landscapes remains largely unresolved [Bouma, 1990; Sposito and Reginato, 1992; NRC, 2001b; Lin, 2003]. Hydrologists may not have a clear picture of flow pathways in the unsaturated zone before initiating modeling or field experiments. Pedologists routinely document in situ pedologic features (such as clay films, ped coatings, soil structures, root distributions, macropores, and hydromorphic features) that are indicative of preferential flow paths and hydrologic regimes. Staining techniques have also been used to indicate flow patterns and to calculate soil hydraulic conductivity [e.g., Bouma et al., 1979]. While qualitative or semiquantitative approaches based on whole-soil interpretations have been used successfully [Boorman et al., 1995], a concerted effort is needed to further quantify the natural "architecture" of soil (soil cover, soil structure, and soil horizonation) in a manner that can be incorporated into models of flow and transport.

[8] 2. Where, when, and how water moves through landscapes and its impacts on soil processes and subsequently soil spatial patterns needs to be better understood. Conceptual and mathematical models for water movement through and over the landscape are key aspects of hydrologic modeling, contaminant transport, and prediction of terrestrial ecosystem functions. However, many current hydrologic models do poorly in predicting subsurface lateral flow and the proportion of surface vs. subsurface runoff inputs into total streamflow [Wood, 1999]. The convergence of surface and subsurface lateral flows within a landscape results in the formation and distribution of wetlands, streams, and rivers, and contributes to the spatial heterogeneity of soils and vegetation across the landscape. Quantification of soil formation/evolution and soil spatial distribution, including flow-restricting layers, can enhance hydrologic modeling and forecasting.

[9] 3. Bridging multiple scales remains at the heart of many hydrologic and pedologic studies. It is highly desirable to explore quantitative means of bridging scales from microscopic (e.g., pores, aggregates) to mesoscopic (e.g., pedons, catenas) and to macroscopic (e.g., watersheds, regional, and global) levels for different hydrologic and pedologic properties and processes. Pedologists study both the mechanisms and the magnitudes of soil spatial diversity as a basis for broad generalizations about soil genesis, classification, and mapping, whereas hydrologists have studied scaling and spatiotemporal variability of hydrologic processes. However, these two efforts have not converged. Joint efforts of pedologists and hydrologists thus would likely shed light on the fundamental processes upon which scale bridging might be possible.

[10] 4. Hydrologists need soil hydraulic parameters in their models, as well as information to specify flow paths, but such data are often lacking or difficult to obtain in large volumes. At the same time, many national and regional soil survey databases developed over the last century have been underused in addressing environmental and ecological issues. Improved procedures are needed to extract useful information from the available databases and to enhance soil survey interpretations for flow and transport characteristics in different soils and landscapes. Bridging data gaps through approaches such as pedotransfer functions [Pachepsky and Rawls, 2004] will be continuously in demand. This will enhance the value of soil survey databases and provide hydrologists with model input parameter estimates. Toward that end, soil categorizations that differentiate various soil hydrologic units (e.g., in terms of flow patterns and transport mechanisms), and quantification of soil morphological features for inferring in situ soil hydraulic properties and water table dynamics are essential research areas. The combined effort of pedologists and hydrologists will provide opportunities for developing integrated databases that are mutually beneficial.

[11] 5. Hydrologists often imply that pedologists view the soil as a static body as they categorize soil characteristics into nondynamic entities (such as grouping soil internal drainage into "well" or "poorly" drained classes). This is a misperception, as pedologists generally have considerable understanding of the implications of these terms for predicting the depth and duration of waterlogging within soils as well as temporal changes in soil water regimes in the medium to long term. Unfortunately, this understanding is not always clearly communicated. Water table fluctuations in soils influence soil water storage capacity and runoff, and thus impact on such hydrologic responses as flood hydrographs, base flow, and solute concentrations in aquatic systems. Regular temporal sampling frameworks are being recognized in pedology, and concerted efforts from pedologists and hydrologists can lead to more complete monitoring data sets that include extreme events (e.g., sediment or solute concentrations in peak flow or sustained drought). A move toward continuous sampling or monitoring of the soil zone will provide better data sets for both pedologic and hydrologic modeling.

[12] The developments in pedology and hydrology are now converging on multiple fronts, as illustrated in the above examples. This convergence leads to synergies that can be expected from integrating the two disciplines, as suggested in recent literature and professional activities [e.g., Lin, 2003; Lin et al., 2005a; Bouma, 2006; Wilding and Lin, 2006]. We believe that integrating hydrology and pedology will enhance the understanding and prediction of 


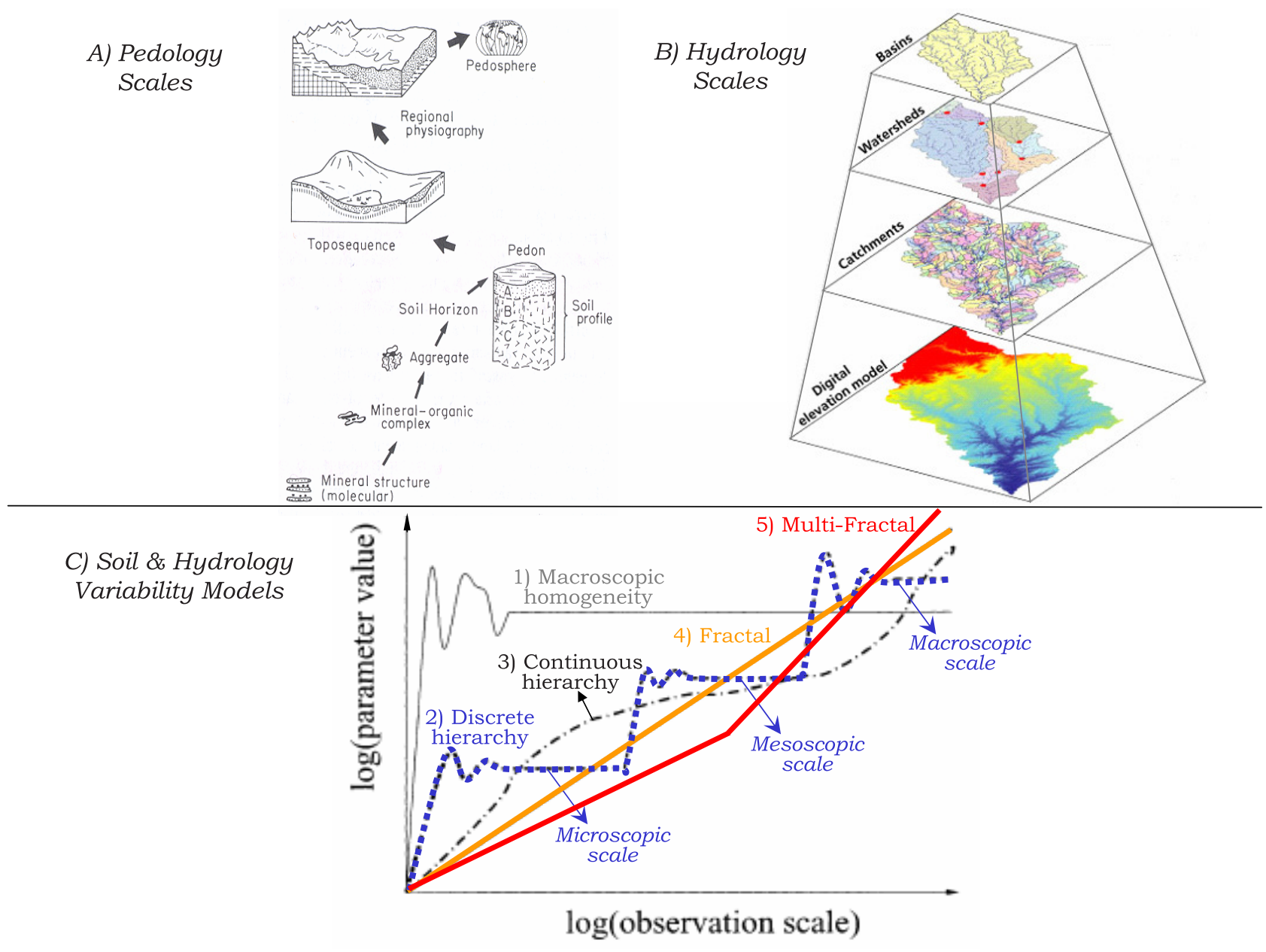

Figure 1. Concepts of scales and spatial heterogeneity in pedologic and hydrologic systems: (a) Conceptual integrated-systems model in pedology [from Wilding, 2000]. (b) Scales of representation of drainage systems [from Maidment, 2002]. (c) Variability models in soil and hydrologic systems that include (1) the classical macroscopic homogeneity (thin gray line), (2) discrete hierarchy (dashed blue lines illustrated at three levels: microscopic, mesoscopic, and macroscopic scales), (3) continuous hierarchy (dash-dotted line), (4) the classical fractal model (thick orange line), and (5) multifractal model (thick red line) (modified from Vogel and Roth [2003]).

water fluxes and flow pathways in landscapes. Such integration also helps answer fundamental questions in unsaturated zone flow and transport, such as the prediction of flow patterns in heterogeneous and structured in situ soils across spatial and temporal scales [Lin, 2005]. It is in such a context that a vision of hydropedology is proposed in this paper.

[13] Hydropedology is viewed here as an intertwined branch of soil science and hydrology that studies the intimate relationships between soil, landscape, and hydrology. Landscape water flux is suggested as a unifying precept for hydropedology, which encompasses the source, storage, flux, pathway, residence time, availability, and spatiotemporal distribution of water (and the transport of chemicals and energy by flowing water) in the soil under both saturated and unsaturated conditions and at a range of spatial and temporal scales. Its spatial scale ranges from microscopy to pedosphere (Figure 1) and its temporal scale encompasses infinitesimal to geological timescales. Hydropedology emphasizes landscape context and in situ soils that have distinct characteristics of pedogenic features, struc- tures, and horizons. It uses pedologic data to improve the performance of process-based hydrologic models, and uses hydrologic data to enhance the understanding of soil variability and its interpretations for soil uses or limitations. Hydropedology may be viewed as a sister discipline of hydrogeology, with the latter traditionally devoted to saturated systems where geological structures prevail, while the former investigating the variably saturated soil zone where soil structures dominate.

[14] The synergistic integration of pedology and hydrology into hydropedology suggests a renewed perspective and a more integrative approach to study landscape-soil-water interactions across scales, and their relationships to climate, ecosystem, land use, and contaminant fate. Working together, we believe, hydrologists and pedologists, along with scientists from related disciplines (such as soil physicists, hydrogeologists, hydrogeophysicists, ecohydrologists, biogeochemists, and atmospheric scientists), can better guide data acquisition, knowledge integration, and model prediction. Similar calls for integration that include microbial and geochemical soil processes could be included but this paper 
focuses on the advantages of the integration of pedology and hydrology.

\section{Research Vision: A Framework for Integrated Hydropedologic Studies}

[15] Among many unresolved scientific issues in pedology and hydrology, some are fundamental. Resolving these key issues can lead to significant improvements in our understanding, measurement, modeling, and prediction of water fluxes across landscapes. Within the context of hydropedology, we suggest five key issues. We present these key issues within a holistic conceptual framework, and attempt to distill a testable hypothesis for each of these issues that will require vigorous testing through concerted efforts from pedologists, hydrologists, and others.

[16] Our suggested framework focuses on quantitative relationships between soil and hydrologic structures and functions at different scales, which serve as the foundation for robust models. At each scale, structure reflects spatial arrangement; function is a result of fluxes or processes. The two-way connection between structure and function is dictated by scale, which also determines observable patterns in spatial variability and temporal changes in the system. The model at each scale (or multiple scales) strives to integrate structure and function so that the patterns and dynamics of the system can be explained and predicted. The challenge here is to build bridges that connect different scales. Anthropogenic forcing (such as land use and land management) is increasingly recognized as being critical, thus must be addressed in integrated hydropedologic studies. The intertwined components of our framework guide the design and implementation of hydropedologic studies, as further explained in the following.

[17] 1. One component is identification of structures: System structure creates constraints and conditions in which processes act and interact. Thus there is a need to identify the interrelationships between hierarchical structures of soil and hydrologic systems.

[18] 2. Another is characterization of functions: Acting and interacting processes create preconditions and feedbacks that modify a system's structure. Hence studies of the functions and structures of soil and hydrologic systems need to be integrated, including, for example, integral characterization of land units in terms of landscape water flux.

[19] 3. Next is bridging of scales: A system's structure and function interact at a variety of scales that define scalespecific variability and pattern. There is a need to identify optimal methods for quantifying and communicating important aspects of soil and hydrologic variability as a function of scale. Scales and scaling in soils need to be correlated with scales and scaling in hydrology.

[20] 4. A fourth component is systematic integration: Models are indispensable tools for integrating the dominant properties and processes at a given scale (or across multiple scales). Soil and hydrologic variability and patterns determine the formulation and application of a suitable model. Pedologic predictive capacity needs to be integrated with hydrologic predictive capacity.

[21] 5. A final component is human impacts: Anthropogenic influences (such as land use and management) on soils and hydrologic systems are intimately linked. Thus soil changes and hydrologic alterations under human impacts need to be addressed simultaneously and be integrated in the context of the landscape or watershed.

[22] Hydrologists and pedologists use different sets of techniques to relate structures and functions at different spatial scales. So far, these techniques have not been combined systematically between disciplines. In many cases, soil structure has been described in pedology without measurements of hydrologic parameters such as the hydraulic conductivity or moisture retention functions. Soil hydrologic measurements, in turn, have often been made with limited attention to soil structure or horizonation. Similar comments hold for larger scales, such as a field where the processes and questions being raised are different. For example, for a hillslope, a soil scientist may define a soil sequence (catena) without paying adequate attention to the spatial pattern of hydrologic properties, whereas a hydrologist may measure hydraulic conductivity without paying sufficient attention to distinctly different soil units. The watershed scale poses yet another set of conditions where geomorphologically defined soil-landscape segments, which may contain one or many soil types and horizons, define a characteristic structure for this scale that may be delineated with geophysical techniques and remote sensing. Systematic integration of pedologic and hydrologic techniques across scales is likely to open new avenues for innovative and complementary sampling and measurement techniques that would contribute to the quantification of our proposed framework and to facilitate the necessary integration.

\subsection{Quantification of Hierarchical Structures of Soil and Hydrologic Systems}

[23] A major difficulty in modeling flow and transport in soils, irrespective of the spatial and temporal scale, is the fact that nature is structured at most or all scales. This can be easily demonstrated by using images of soil structure obtained at various scales from as small as soil thin sections to as large as remotely sensed soils information from satellites. As a consequence, measurement will depend on the support scale of the instrument used. To achieve the goal of characterizing and modeling functions of soil and hydrologic systems across scales, we need to find ways to quantify soil-landscape structures at various scales. Probabilistic or fuzzy logic approach could be used to discriminate between fast flow and slow flow domains forming a pattern that reflects the observed structures. Identification of soil-landscape structures allows enhanced understanding of flow pathways and processes (e.g., preferential flow). Thus future investments should focus on the spatial structure of material properties rather than on point measurements. This perspective is in line with our perceived need for studying patterns described in the next section.

[24] A relevant hypothesis to be tested is suggested as follows.

Hypothesis 1. Soil systems and their hydrology exhibit hierarchical structures (discrete or continuous) that can be quantified using soil-landscape expertise, coupled with an appropriate set of measurement techniques (noninvasive and invasive).

[25] Strategies are needed to quantify spatial structures of soil and hydrologic systems at different scales. These 
include advanced instruments and measurement techniques that are essentially noninvasive (e.g., computed tomography, geophysical tools, and remote sensing). These tools are all sensitive to some material properties and generate proxy measurements that can be related to those required by hydrologic models. An essential part of this is to further develop fundamental insight into such proxy relationships or pedotransfer functions. One important issue is to identify critical and/or rare structural information that governs hydrologic processes at different scales. More specific techniques are discussed in section 3.2.

[26] Direct detection and quantification of soil and hydrologic spatial structures is typically difficult and expensive. To make progress, we need to explicitly recognize that the observed structures are not an arbitrary outcome of unknown random processes but the result of structure-forming processes that can be identified and understood. Hence an attractive approach is to use all available knowledge of soil structure-forming processes (including the distribution of aggregates within a soil and the distribution of various soils within the landscape). This knowledge exists and is continuously being generated and updated in various branches of soil science, especially pedology. These disciplines have evolved far too separately from hydrology. Consequently, joining the soil and hydrologic sciences within a hydropedologic framework would advance our capability to understand and predict flow and transport processes and pathways in the field.

[27] The soil structure-forming process is tightly linked to pedogenesis, an integrated phenomenon resulting from a series of physical, chemical, and biological processes. Pedogenesis provides a holistic view of the processes that have occurred, or are occurring, in the soil zone in different geographic regions under the influences of climate, organisms, geology, topography, and time (i.e., the five natural soil-forming factors). Besides conceptual understanding of soil-forming factors and processes [Jenny, 1941; Simonson, 1959], quantitative models that describe the impact of environmental variables on rock/sediment weathering and soil-geomorphology evolution over time are critically needed. Because water plays an essential role in soil formation and soil dynamic changes, pedogenesis contains valuable information regarding hydrologic processes involved in soil-landscape evolution. Adequate understanding of quantitative soil-forming processes can lead to enhanced characterizations of soil and hydrologic hierarchical structures.

\subsection{Identification and Prediction of Functional Patterns}

[28] Identification and prediction of patterns, or repeated spatiotemporal organization, across scales is becoming a leading area of research in soil science and hydrology [Grayson and Blöschl, 2000; Lin et al., 2005a]. Patterns offer rich and comprehensive insight regarding the variability of structures and functions, as well as the underlying processes controlling hydrologic response [Grayson et al., 1997; Grayson et al., 2002; Lin et al., 2006]. A number of recent catchment-scale hydrologic field investigations have demonstrated how the understanding and modeling of hydrologic processes can be improved by the use of observed spatial patterns [Grayson and Blöschl, 2000]. Some spatial patterns are temporally persistent, the notion of "time stability" [Vachaud et al., 1985; Kachanoski and de Jong, 1988; Mohanty and Skaggs, 2001; Lin, 2006], which may be a function of spatial scale and may vary across a landscape with different soil types [Kachanoski and de Jong, 1988; Zhang and Berndtsson, 1991; Lin, 2006]. Western and Grayson [2000] found that combining spatial patterns with temporal responses added value to both type of observations in a modeling context, and improved the confidence with which the spatiotemporal organization of soil moisture could be predicted.

[29] There is a great need for innovative characterization and modeling of spatiotemporal patterns at different scales that are important to pedologic and hydrologic phenomena. Such approaches will likely use a combination of ground-based observations, digital geospatial data layers (e.g., digital elevation models or DEM, surficial geology, and land cover), noninvasive geophysical/hydrogeophysical methods (e.g., electromagnetic induction, ground-penetrating radar, radiometry), and remote sensing imagery, along with 3-D landscape-scale flow modeling. The optimal combination, integration, and assimilation of these multiple techniques and data sources, possibly with the use of inverse methods [Yeh and Šimunek, 2002], will provide substantially better information regarding spatiotemporal organization of pedologic and hydrologic phenomena across scales. For example, McKenzie and Ryan [1999] used a variety of data sources including topography, geology, climate, and airborne gamma radiometric data as predictors of soil properties. Techniques for combining remote sensing imagery with hydrologic models are also rapidly developing and are enabling better use of remote sensing observations at large (regional to global) scales. Some progress has been made in using remote sensing of hydrologic response to infer soil properties and vice versa [e.g., Hollenbeck et al., 1996; Jackson and Le Vine, 1996].

[30] A relevant hypothesis is suggested here.

Hypothesis 2. The storage, flux, pathway, and residence time of water in the soil-landscape can be used to subdivide landscapes into similarly functioning hydrologic units.

[31] The functional unit concept based on characterization of 4-D (3-D + time) soil units within fields allows reliable quantification of fluxes within those fields. Hydrologically similar soil-landscape units exist within watersheds and these can be identified using traditional and new techniques and data sources. Winter [2001] proposed the concept of a "fundamental hydrologic landscape unit" as a means to divide a landscape into its most basic forms: upland and lowland separated by a steeper slope. Each of these units has specific characteristics, including land surface form, geology, and climate, which then together control its hydrology. This concept of fundamental hydrologic landscape units has been embraced by Reed et al. [2006] in addressing human and climate impacts on bridging river basin scales and processes. In the context of hydropedology, soil-landscape relationships and soil hydrologic characteristics are emphasized in defining similarly functioning hydrologic units over a landscape.

[32] Note that some differences within fields, as distinguished by pedologists, do not always correspond with 
hydrologic functional differences. Wösten et al. [1985] transformed soil patterns on detailed soil maps into patterns of "functional units" that each had distinctly different hydraulic conductivity and moisture retention characteristics. In doing so, the number of spatial units on the map was reduced by 30\%. Breeuwsma et al. [1986] did the same but for cation exchange capacity and phosphorous adsorption capacity, resulting in reductions of $20 \%$ and $30 \%$, respectively. A more sophisticated procedure was followed by Bouma et al. [2002] who delineated "management units" for precision agriculture on the basis of simulation runs for nitrogen transformations and pesticide leaching for point data, followed by interpolation. Knowing the internal variability within these "management units" allows estimates to be made of the variability obtained for simulation runs for the units.

[33] In identifying and predicting soil hydrologic patterns, soil morphology has a unique role to play. Soil morphological attributes (such as redoximorphic features, structure, and ped/void surface features) and their spatial arrangement over the landscape can be used to aid in determining dominant flow pathways and fluxes. For example, frequency and importance of preferential pathways may be inferred using the geometry and distribution of interpedal pores, clay films, and worm channels. By using staining techniques, preferential flow pattern can be further quantified, linking to soil structure and macropore continuity and connectivity [Booltink and Bouma, 2002]. Because soil morphology provides clues as to the hydrologic history of a site by integrating the long-term effects of water flow and storage in observable features of soil color and other properties (e.g., redox features), efforts to interpret and quantify soil morphologic data can elucidate hydrologic patterns (such as seasonal high water table and soil drainage). It is encouraging that some preliminary attempts have been made to hydrologically classify soils and to predict water movement through different soils and substrates [Quisenberry et al., 1993; Boorman et al., 1995; Lilly et al., 1998]. However, a more comprehensive and quantitative approach to grouping hydrologically similar soil types across scales is needed.

[34] We realize that predicting preferential flow from soil morphologic information is still in its infancy, and that preferential flow may be caused by a multitude of processes, including some that are not immediately evident from classic pedologic studies (e.g., unstable flow). One of the key issues is the need to quantify soil morphology, including pore structure, in a manner that provides direct information for inclusion in hydrologic models. We envisage the appearance of innovative methods for quantifying in situ soil morphology and soil structure and then linking such information to hydrologic processes/properties in a quantitative manner.

\subsection{Bridging Multiple Scales}

[35] Translating information about soil and hydrologic properties and processes across scales has emerged as a major theme in contemporary soil science and hydrology [Kalma and Sivapalan, 1995; Sposito, 1998; Hoosbeek et al., 1998; Western et al., 2002; Pachepsky et al., 2003]. As remote sensing techniques for estimating large-area soil and hydrologic properties and in situ measurements for local areas continue to be developed, bridging multiple scales becomes even more essential. At present, no single theory exists that is suitable for spatial aggregation (or upscaling), disaggreagation (or downscaling), and temporal inference (or prediction) of soils and hydrologic information. The major complementary approaches include scaling via defined hierarchies, and continuous models of spatial variation as described by fractal theory and geostatistics [Lin and Rathbun, 2003; Pachepsky et al., 2003]. Further exploration of this topic is critical.

[36] Hierarchical frameworks have been conceptualized by pedologists as a means for organizing soil systems from the soil pore scale to the global pedosphere (Figure 1) [Hoosbeek and Bryant, 1992; Wilding, 2000]. Hierarchical complexity has been studied in pedology, which has long recognized self-organized complexity in the processes of soil formation, with taxonomic frameworks constructed to summarize that ordering [Buol et al., 2001]. However, a quantitative hierarchy of soil systems that could be integrated into models of flow, scaling, and rate processes is still lacking. Sommer et al. [2003] recently presented an integrated method for soil-landscape analysis, in which a hierarchical expert system was developed for multidata fusion of inquires, relief analysis, geophysical measurements, and remote sensing data, as well as a combination of the soil-forming factorial model of Jenny [1941] with the scaleway approach of Vogel and Roth [2003] to address soil variability across scales.

[37] There are several approaches in hydrology and soil physics to incorporate spatial heterogeneity into flow and transport modeling, including macroscopic homogeneity, discrete hierarchy, continuous hierarchy, and fractals (Figure 1). Vogel and Roth [2003] suggested a "scaleway" approach for predictive modeling of flow and transport in the subsurface at any scale. Their conceptual approach is based on the explicit consideration of spatial structure that is assumed to be present at any scale of interest, where the microscopic heterogeneities may be replaced by an averaged, effective description. Some studies [Cushman, 1990; Bouma, 1992; Vogel et al., 2002] have suggested a discrete hierarchy of the representative elementary volume (REV), where the REV is a local property related to a given level of soil structural unit. This is consistent with the hierarchical organization of soil aggregates that is characteristic of most soils [Tisdall and Oades, 1982; Oades and Waters, 1991]. However, quantification of soil structure and its impacts on flow and transport in field soils remains unresolved. A versatile geometric foundation for representing porous media (e.g., fractal geometry and percolation theory) is emerging as one of the possibilities for achieving improvements in media scaling, flow modeling, and soil hydraulic function characterization [Crawford et al., 1999; Jury, 1999; Gerke and van Genuchten, 1996; Hunt, 2005]. Further progress requires joint efforts of pedologists, hydrologists, mathematicians, and related discipline scientists.

[38] A hypothesis to be tested is suggested here.

Hypothesis 3. Scale dependence in hydrologic parameters can be explained using hierarchical structures in soils, landforms, and land cover.

[39] Changing scales in soil and landscape studies involve changes in the type of information obtained about 
the system, in parameters used to characterize the system, in the system's variability, and in the observability and predictability of the system. Accordingly, a scale transition generally includes a change in preferred hydrologic flow model (e.g., Navier-Stokes $\rightarrow$ Richards' equation $\rightarrow$ water mass balance equation) and a change in structure characterization in pedology (e.g., aggregate structure $\rightarrow$ profile structure $\rightarrow$ soil-landscape structure). It is the system's scale that determines the processes or "physics" involved, and only when the physics is understood can a suitable flow model be developed and the relevant material properties be identified. Faybishenko et al. [2003] suggested a triadic approach to scaling in which material properties from the finer scale are used to estimate model parameters for the scale in question, whereas system properties from the coarser scale are used to establish constraints for model behavior. An exhaustive characterization of structure at each scale should describe rare structural features that, in actuality, may define the hydraulic behavior at the coarser scale [Pachepsky et al., 2004]. Connected macropores that are rare at the soil horizon scale presents an example of such a feature since they define soil hydraulic behavior under high water content at the soil profile scale. Scale-specific delineation of rare structural features and characterization of their hydrologic role requires a concerted effort from pedologists and hydrologists.

[40] Hierarchy theory in ecology [O'Neill et al., 1986, 1989] presents some valuable philosophical and operational concepts pertaining to the quantification of hierarchical structures of soil and hydrologic systems [Haigh, 1987; Wagenet, 1998; Lin et al., 2005a]. If properly constructed, a hierarchy of soil systems should reflect logical links and quantitative relationships among scales. It can be argued, however, that the hierarchy of scales as used by soil scientists is often more of an operational or observational device based on the ability or feasibility to measure the properties involved, rather than reflecting fundamental differences in the basic processes [Wagenet, 1998]. Hierarchy theory in ecology defines "holons," which are nested spatial units characterized by means of integrated biological, physical, and chemical processes [Haigh, 1987]. In comparison, soil science uses entities that are generally less well defined and procedures that are less well integrated. Further studies in this area of research are worthwhile.

\subsection{Integrated Models and Databases}

[41] Many current hydrologic models are either "too good to be real" or "too real to be good." In the first case, oversimplification compromises the accuracy or generality of the results. In the second case, the need for detailed input data renders the model impractical to apply except in a research setting. Compromises between the quest for perfection and the complex reality, compounded by our limited knowledge, available modeling technology, and/or suitable data, plus natural uncertainty, are facts of life. The notions of multiplicity and site specificity of hydrologic models are now gaining evidence and acceptance in hydrology [Beven, 2000]. It is therefore best to consider a broad range of reasonable alternative hypotheses and to base the model on a variety of different types of data [NRC, 2001b]. Armed with advances in categorizing soil-landscape relationships and cataloging existing structures, pedology has a potential to contribute substantially to building a range of hypotheses that should be considered in hydrologic modeling. Needs of hydrologic modeling, in turn, may catalyze efforts on organizing available soils information in forms that are more relevant to hydrologic modeling needs. Pedology has already provided a spectrum of pedotransfer functions to be used in hydrologic model parameterizations [Pachepsky and Rawls, 2004]. More can be expected as information on soil structure and landscape features are being incorporated into pedotransfer functions [Rawls and Pachepsky, 2002; Lilly and Lin, 2004; Lin et al., 2005a]. In addition, as the importance of prior model parameter estimates along with posterior estimates from calibration becomes recognized, soil-landscape databases and pedotransfer functions can serve as useful sources of prior estimates. The need to use a broad range of data warrants efforts in developing a quantitative framework for linking soil hydrology to climatic, pedologic, topographic, and vegetative processes and for linking data collected at different scales of spatial support. Data assimilation and data fusion may improve the operational use of hydrologic models at large scales by supporting model testing, verification, and refinement.

[42] A relevant hypothesis is thus suggested here.

Hypothesis 4. Soil-landscape relationships can improve the accuracy and the reliability of pedotransfer functions and hydrologic model predictions at the landscape level.

[43] The most important step in any modeling application is to determine what is important to system behavior. In modeling catchment response, determining the dominant processes and flow pathways that are responsible for controlling hydrologic response at different space and time scales enables development of appropriate conceptual models that then form a basis for quantitative simulations of system response. Mixtures of different processes control hydrologic responses in different landscapes. Hydrologic modelers at present often struggle to determine what the dominant processes and flow paths are in a particular landscape, unless these have been studied in detail. However, we believe that there is great potential to improve predictions through more innovative use of soil survey data, and through certain modifications of the base data being collected during soil surveys. It is important to note that, as interests shift to issues involving the transport of solutes and sediments driven by water flow, the hydrologic models need to predict first and foremost the flow paths correctly and then the associated fluxes, i.e., they must be accurate for the right reasons, something that is not necessarily needed for acceptable predictions of integrated catchment runoff at the watershed scale.

[44] Another area where modelers are challenged is in developing system descriptions that work well across scales [Beven, 2002]. This is partly because different processes become dominant at different scales, partly because the detail of information available typically decreases as one moves up in scale, and partly because the level of detail that can be represented reduces at larger scales due to the pragmatic constraint of computing. These effects have a number of implications that complicate modeling. At microscales, water flow is controlled by capillarity and laminar flow through individual pores and around peds. As scale increases, flow often becomes controlled by impeding 
layers in a soil profile, then accumulation of water downslope leading to surface saturation, and finally routing of flow through a stream network. This change in the dominant process with scale implies that the model structures change with the scale of application. Data availability is also changing with scales. It is possible to characterize individual pores in a thin section but not yet for an entire soil profile. Likewise, it is possible to characterize a soil profile in detail in a soil pit, but it is not yet possible to characterize the 3-D soil entity to the same level of detail, even for a first-order catchment. This is fundamental since properties are spatially variable. This means that some form of average or statistical representation of small-scale detail may be required in models, even if the model resolves the system with a fine numerical grid in space and time. Although limits on computing power will become less a concern in the next decade or so, larger spatial and temporal units are generally used for larger scale models. An implication of this is that clever algorithms are required that capture the effects of unresolved or unrepresented small-scale processes, spatiotemporal variability of these processes, and the nonlinearities that typify environmental processes [Vander Kwaak and Loague, 2001; Panday and Huyakorn, 2004].

[45] Besides the complexity of spatial scale, we also stress the critical importance of temporal dimension. The timescales over which soil and hydrologic processes occur range from milliseconds for soil chemical reactions to decades or longer for transport of solutes to groundwater, with some processes occurring only sporadically and also changing under different conditions or seasons. In addition, there is often a disjunction between soil and land use interactions and the subsequent impacts on aquatic systems. For example, nitrate is leached from soils in temperate agricultural systems largely during the winter but the impacts on aquatic ecology are often seen in the summer at some distance away from the original source [Ferrier and Edwards, 2002]. Therefore measurement frequency must be aligned to the temporal variability and the structure (e.g., runoff events) inherent in pedologic and hydrologic processes. An adequate understanding and appropriate representation of temporal variability, the scales over which different processes operate, and the disassociations between sources and impacts, is vital to the development of robust models that can simulate hydropedologic processes, watershed response, and environmental dynamics. Analogous to the REV, perhaps a concept of "representative elementary time step" might be explored for characterizing temporal variability of pedologic and hydrologic phenomena.

[46] Associated with modeling and prediction is the obvious need of integrated databases that are consistent and interoperable. Soil survey databases provide a wealth of information that hydrologists could utilize for various applications. These databases can be potentially utilized in the development of pedotransfer rules and functions, hydrologic grouping or classification of soils, and testing of hydrologic models. However, it is also important to recognize that traditional soil survey databases do not contain much information on dynamic soil properties required for deriving reliable pedotransfer functions (except perhaps for specific retention points such as wilting point or field capacity). Most data in traditional soil survey databases have been collected at a window in time. Hence, to enhance the value of classical soil survey databases and to facilitate the integration of pedology and hydrology, concerted efforts are needed to develop landscape-based new generations of pedotransfer functions. We believe that hydropedology offers a useful framework for bridging traditional soil survey and future databases of dynamic soil properties through incorporating specific information on soil structure, horizonation, landform, and land use.

\subsection{Human Impacts and the Concepts of Soil "Genoform" and "Phenoform"}

[47] With increasing emphasis on human impacts and land management practices, the dynamics of soil and hydrologic properties requires more attention in hydropedology. Anthropogenic influences on soils have resulted in distinct characteristics that can be used to classify and model naturally formed soils under different land management scenarios. The concepts of "genoform" (for genetically defined soil series) and "phenoform" (for soil types resulting from a particular form of management in a given genoform) [Droogers and Bouma, 1997] facilitate the incorporation of management effects into pedologic and hydrologic characterizations and could potentially enhance pedotransfer functions that involve soil series and land use classifications as carriers of soil hydraulic information [Pulleman et al., 2000; Sonneveld et al., 2002]. The distinction between major soil management types (phenoform) within the same soil series (genoform) separates the morphogenetic properties used in soil taxonomic units from near surface temporally dynamic properties used in cartographic units delineating management driven effects.

[48] Grossman et al. [2001] also suggested use-dependant properties as those soil properties that show change and respond to soil use and management (such as soil organic matter levels and aggregate stability), and use-invariant properties as those soil properties inherent from natural soil-forming processes that show little change over time and are not affected much by soil use and management (such as mineralogy and particle size distribution). Usedependent properties are mostly evident in surface soils.

[49] A possible hypothesis in this area of research is as follows.

Hypothesis 5. The concepts of "genoform" and "phenoform" combined with pedotransfer functions for separate soil horizons can improve the efficacy of soil series and land use classifications as carriers of soil hydraulic information under different human impacts.

[50] Any given soil can be changed significantly by land use and management practices, even though soil classification remains the same. For example, Droogers and Bouma [1997] studied a prime agricultural soil in the Netherlands and found that the organic matter content of a conventionally tilled variant had significantly decreased as compared with a variant subject to organic farming. Also, grassland had even higher organic matter contents even though soil classifications of these three phenoforms were identical. Pulleman et al. [2000] showed that organic matter contents of these phenoforms could be predicted by regression analysis as a function of previous land use. Modeling crop growth and nitrate leaching to the groundwater yielded 


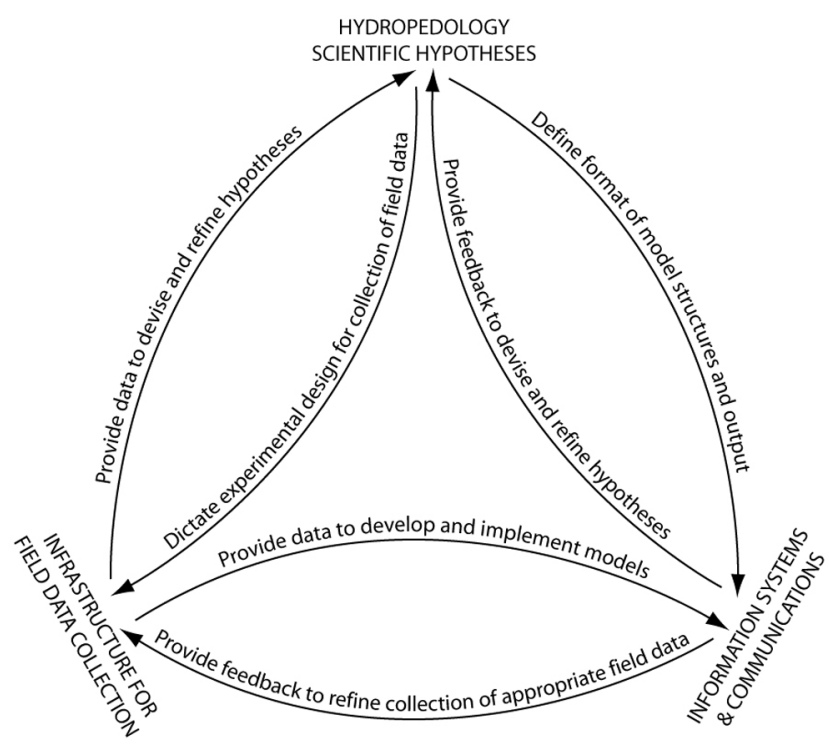

Figure 2. Schematic of the iterative loop and interactions between the strategies for achieving the research vision proposed in this paper.

significantly different results for these phenoforms. This concept addresses one of the main limitations of soil maps that show genetic and static classification of soils, i.e., soils with very different properties caused by different management histories are classified as the same soil type on the basis of natural soil-forming factors. Pedotransfer functions often use organic matter content and bulk density as input parameters, which can vary significantly among different phenoforms. Distinguishing different phenoforms for a given genoform (or soil series) can refine the dynamic characterization of soils and pedotransfer functions under different human impacts, which will undoubtedly enhance hydrologic modeling and prediction. Sonneveld et al. [2002] made such an analysis for a major sandy soil in the Netherlands.

\section{Strategies for Achieving the Vision: A Global Perspective}

[51] We suggest some interlinked strategies for achieving the above stated vision, including (1) design of a set of scientific experiments to test the proposed hypotheses and (2) use of hydrologic observatories and natural soil laboratories for systematic field data collection and synthesis (Figure 2).

[52] We would like to point out that, while devising more detailed experimental and modeling work as proposed in the following, a useful first step in hydropedology is to link existing soil and hydrologic data (such as grouping hydrologically similar soil units and enhancing pedotransfer functions) to demonstrate the applicability of soils data to hydrologic research. This will be enhanced by case studies on the use of pedologic data for improved hydrologic applications (such as knowledge of flow pathways at the pedon and field scales and of hydrologic responses at the watershed scale) [e.g., Quisenberry et al., 1993; Boorman et al., 1995; Lilly et al., 1998; Dunn and Lilly, 2001]. The knowledge gaps thus identified can then be used to guide more detailed fundamental research.
[53] It is also important to recognize that adequate and effective communication with scientists in other disciplines, the general public, stakeholders, educationalists, and policy makers is needed to advance hydropedology and to demonstrate its unique strengths and practical applicability. For example, early engagement with multidisciplinary scientists and stakeholders and throughout the length of a project is more likely to lead to an acceptance and implementation of project results. This may be particularly crucial in parts of the world where there is a stronger affinity with soil and water resources [Bouma, 2001a, 2001b, 2003, 2005].

\subsection{Design and Implementation of a Systematic Set of} Scientific Experiments to Test the Proposed Hypotheses

[54] Designing a set of scientific experiments that can test the suggested hypotheses is a logical step in achieving the proposed research vision. The suggested hypotheses can be used to guide the design and implementation of such experiments. We believe that these experiments are best conducted in a coordinated fashion among international soil and hydrologic communities in order to maximize results. A variety of factors including infrastructure support (such as hydrologic observatories), available funding, cutting-edge instruments, innovative techniques, integrated databases, and multidisciplinary communications are all integral part of successful community-based science.

[55] Much progress has been made in 1-, 2-, and 3-D modeling, in terms of integrating various processes at different scales and incorporating preferential flow dynamics [van Genuchten and Simunek, 2004], but much remains to be done, especially in bridging scales, deriving inputs, quantifying uncertainties, and integrating processes from a systems perspective. Integrated models are the future, where overland flow (including rivers and lakes), ecohydrology, vadose zone flow and transport, and groundwater hydrology are tightly coupled. Running models of this type for various applications will help in deciding which hypotheses are fundamental and what data are critical.

[56] To make a quantum leap, we need to embrace a holistic framework such as the one discussed in section 2 and to find ways to build comprehensive data sets for quantifying such a framework, as further explored in section 3.2. Beyond problem-solving needs, we have to address fundamental concepts and first principles involved in landscape to river basin hydrology, and to take full advantage of signatory information recorded in soils (such as soil hydromorphology and pedogenesis related to hydrology). One way to follow such a path is to advance our understanding of a system's logical connections such as "structure-physics-flow model" and the related five critical issues as discussed in section 2.

\subsection{Use of Hydrologic Observatories and Natural Soil Laboratories for Multiscale, Multidisciplinary, and Long-Term Field Data Collection and Synthesis}

[57] One critical need for advancing hydropedology is a network of well-designed and carefully maintained experimental watersheds or natural laboratories across a wide range of geographic regions for systematic (in both space and time) field data collection. The soil science and hydrology communities have long recognized the fundamental need for multiscale, multidisciplinary, and long-term field data collection and synthesis, including better archiving and sharing of field data across geographic regions [e.g., $N R C$, 
1999, 2001a]. Although there have been various field experimental networks in the United States (such as the experimental watersheds of the USDA Agricultural Research Services, the large river basin gauging stations of the U.S. Geological Survey, the pollution monitoring sites of the U.S. Department of Energy, and the experimental stations of many land grant universities), better integration and coordination across agencies, disciplines, and scales is needed to address "big" science questions. In the context of hydropedology, we feel the need for better coordinated and integrated studies to develop principles governing the relationships between soil, landscape, and hydrology at a range of spatial and temporal scales.

[58] We note that an iterative loop of "understanding, sampling, and modeling" is essential to integrated hydropedologic studies. It is important to point out the need for process-based modeling in conjunction with the data gathering. Data are only valuable if they are used, not just by users or policy makers, but even more so by peer scientists including those interested in advancing hydrologic modeling. Future modeling needs could provide both justifications and guidelines for all the measurements to be made, including "what, where, and when" data should be collected, at what resolution, for how long, and for what purpose. Systematic field data collections must contribute to enhanced understanding at a variety of scales and to the advancement of quantitative modeling and prediction.

[59] In carrying out field data collection, commonly accepted and adhered to protocols must be adopted and utilized in hydrologic observatories and natural soil laboratories across geographic regions. Contrasting soil-landscapes and experimental watersheds of different geology, climate, and land uses need to be considered. Hydropedology can contribute uniquely in this regard in ways that include (1) the use of the state-of-the-art techniques in soil mapping, vadose zone monitoring, and variably saturated modeling and (2) attention to field soil morphology and soil distribution patterns to guide the selection of monitoring sites, optimal experimental designs, interpretations and synthesis of experimental data, and flow and transport modeling. We believe that a minimum set of hydropedologic data should be collected in order to characterize a catchment and its hydrologic flux dynamics. Determination of such a core data set will be guided by the scientific hypotheses to be tested, interpretation techniques required for the collected data set, improvements for quantitative modeling and prediction, as well as the needs for the overall integrated monitoring network. Research conducted at hydrologic observatories and natural soil laboratories will also allow for the testing and refinement of pedometric approaches to mapping critical hydropedologic variables and scaling pedon data to the landscape scale.

[60] Cutting-edge instrumentation and innovative measurement techniques are integral part of hydrologic observatories and natural soil laboratories, such as (1) networked arrays of state-of-the-art sensors (ground-, air-, and spacebased platforms) for measuring states and fluxes at point, hillslope, catchment, and regional scales and at critical time steps (e.g., in situ soil moisture sensors, optical and microwave imagery, radiometry, hyperspectral imagery, and others); (2) a suite of noninvasive tools (e.g., computed tomography, geophysical tools, and remote sensing) for characterizing soil-landscape structures across multiple scales and for linking such structural information to water fluxes in a block of land of various sizes; (3) enhanced tools and methods for measuring and representing landscape-scale soil hydraulic parameters such as soil hydraulic functions; (4) advanced soil and landscape mapping that captures spatial and temporal patterns of hydropedologic properties and processes; and (5) a set of natural and anthropogenic tracers for tracking the movement of water through landscapes and river basins.

[61] To advance hydropedology and hydrologic modeling, we need new ways of mapping soils and landscape features in greater detail and with higher precision. Several important issues need to be addressed in this regard.

[62] 1. Traditional soil maps have been created using conceptual models of soil formation modified to suit local conditions [Dijkerman, 1974; Soil Survey Division Staff, 1993], resulting in qualitative models that discretize the soil continuum [Hudson, 1992; Cook et al., 1996]. The classical distinction of sharply bounded soil units on soil maps is not realistic as soil boundaries tend to be more gradual. This realization is essential for flow processes. Even though work has been done with fuzzy sets to create gradual soil boundaries, this has yet to be translated into hydrologic characteristics used for process modeling. Proper use of existing soil maps also requires adequate understanding of map scale and within-map-unit variability. Quantification of map unit purity for different scales of soil maps and its applicability for hydrologic modeling is an area needing improvements in modern soil surveys [Arnold and Wilding, 1991; Lin et al., 2005a, 2005b]. With the emergence of quantitative pedologic measurements and modeling techniques [e.g., McBratney et al., 2000; Heuvelink and Webster, 2001; McBratney et al., 2003], quantitative models of soillandscape relationships are expected to improve hydrologic modeling. These include environmental correlation modeling [McSweeney et al., 1994; McKenzie and Ryan, 1999; Park and Vlek, 2002] or landscape-guided soil mapping [Heuvelink and Webster, 2001], and combined use of GIS, expert knowledge, and fuzzy logic [Zhu et al., 2001].

[63] 2. Soil maps can no longer be static documents. Rather, derivative maps created for specific purposes or functions, and dynamic maps reflecting changes caused by land use and management, must be generated or updated from original soil maps and tailored to particular applications. Thus pedotransfer functions, in combination with computer models and geospatial data layers, need to be integrated into expert systems to derive such maps. Thus far, there has been a conspicuous lack of appropriate means of producing derivative and dynamic soil maps such as soil hydraulic properties through space and time.

[64] 3. Even though high-resolution DEM are widely available, they cannot as yet be matched well with the underlying soil characteristics that determine, together with the vegetation, infiltration and runoff. A well-defined match needs to be established between hydrologic units being considered and the corresponding soil and landscape data sets. New techniques using various types of geophysical tools and remote sensing are needed to fill this gap. However, although remote sensing techniques offer significant opportunities to infer the state of soils and their properties, remote sensing signals are typically only sensi- 
tive to a very limited surface depth. This surface information needs to be linked to a reliable model of soil-landscape relationships to infer subsoil properties and to project point observations to landscape scales. Extending sensor capabilities to gain more vertical information for describing the 3-D nature of the soil would be desirable. Pedotransfer functions utilizing remote sensing and geophysical inputs could also be used to assist in reducing the degree of freedom in hydrologic models (thus reducing the uncertainty) by providing hydropedologic constraints and patterns that are either quantitative or qualitative. Correlating geophysical signals with soil profile characteristics (such as restricting layers, soil structures, and soil moisture) as well as soil map units can greatly enhance the development of proxy relationships needed in hydrogeophysics.

[65] There is a clear need for integrating knowledge, databases, and models to address forcing, feedbacks and coupling, and to ensure appropriate spatial coverage, temporal frequency, and data resolution. Besides data models [e.g., Maidment, 2002], an integrated process-based modeling system is also needed that allows systematic examination of various processes at different scales. In doing so, code standards (such as algorithm transferability, modularization, and object-oriented design) and intercode comparison (especially against field data collected in experimental watersheds and natural soil laboratories) need to be considered [Šimunek et al., 2003]. We recognize the need for balancing standardizations and innovations in both field data collections and modeling system developments so as to provide common protocols for data gathering and sharing and model comparison while not constraining new approaches to data collection and modeling. Innovative syntheses of hydrologic and pedologic data with new tools/methods for data mining and knowledge discovery are also important for advancing hydropedology.

\section{Conclusion}

[66] Hydropedology is a timely addition in this exciting era of interdisciplinary and systems approaches for developing a comprehensive prioritization of science and its applications in the hydrologic sciences. Hydropedology proposes to realign geology-rooted classical pedology with a hydrology-driven approach based on a landscape perspective, reflecting the crucial role of water in wide array of issues. Hydropedology focuses on the interface between the hydrosphere and the pedosphere and emphasizes flow and transport processes in field soils as they occur in the landscape. We believe hydropedology is a promising direction for the future of pedology as it adds quantitative hydrologic and soil physical information to classical pedology, including (1) measuring rather than estimating soil moisture regimes and water fluxes, (2) improving soillandscape modeling and soil mapping through appropriate attention to landscape water fluxes, (3) quantifying soil drainage classes and modeling soil dynamic changes under different land uses and managements, and (4) making soils databases more relevant and reliable for hydrologic modeling. On the other hand, pedology can make a unique contribution to enhance the understanding and prediction of landscape water flux, including (1) providing better data on soils and water flow pathways (e.g., those related to soillandscape structures, preferential flow, and lateral fluxes over slowly permeable soil horizons), (2) enhancing the understanding of mechanisms and magnitudes of soil spatiotemporal variability (e.g., soil spatial diversity as a function of soil-forming factors and processes), (3) improving the quantification of structural hierarchies and identifying patterns of soil and hydrologic systems (e.g., quantitative soil-landscape relationships and soil hydrologic units as portrayed by soil maps of various scales), and (4) enhancing model structure formulation and selection of suitable models for hydrologic predictions. Integrating pedology and hydrology into hydropedology will make an important contribution to the advancement of the hydrologic sciences as well as soil science in the next decade and beyond.

[67] Acknowledgments. Funding provided by the Consortium of Universities for the Advancement of Hydrologic Sciences, Inc. (CUAHSI), through the support from the National Science Foundation, has made this opinion paper possible. Members of our initial team of Hydropedology and the Earth's Critical Zone included: Lawrence Band, Johan Bouma, Kristofor Brye, Christopher Duffy, James Famiglietti, Rodger Grayson, Allan Lilly, Henry Lin, Alex McBratney, Yakov Pachepsky, James Thompson, Scott Tyler, M. T. van Genuchten, Michael Vepraskas, HansJörg Vogel, and Andrew Western. The interest and support of all our initial team members are greatly appreciated. Valuable review comments provided by Andrew Binley and two anonymous reviewers significantly enhanced the quality of this paper.

\section{References}

American Association for the Advancement of Science Council (2001), Report of the 2001 AAAS Council meeting, Science, 292, 2509.

Arnold, R. W., and L. P. Wilding (1991), The need to quantify spatial variability, in Spatial Variabilities of Soils and Landforms, edited by M. J. Mausbach and L. P. Wilding, Spec. Publ. Soil. Sci. Soc. of Am., 28, 1-8.

Beven, K. (2000), Uniqueness of place and nonuniqueness of models in assessive predictive uncertainty, in Computational Methods in Water Resources XIII, edited by L. R. Bentley et al., pp. 785-792, A. A. Balkema, Brookfield, Vt.

Beven, K. (2002), Towards an alternative blueprint for a physically based digitally simulated hydrologic response modeling system, Hydrol. Processes, 16, 189-206.

Blöschl, G., and R. Grayson (2000), Spatial observations and interpolation, in Spatial Patterns in Catchment Hydrology: Observations and Modeling, edited by R. Grayson and G. Blöschl, pp. 17-50, Cambridge Univ. Press, New York.

Booltink, H. W. G., and J. Bouma (2002), Suction crust infiltrometer and bypass flow, in Methods of Soil Analysis, part 4, Physical Methods, edited by J. H. Dane and G. C. Topp, pp. 812-815, Soil Sci. Soc. of Am., Madison, Wis.

Boorman, D. B., J. M. Hollis, and A. Lilly (1995), Hydrology of soil types: A hydrologically-based classification of the soils of the United Kingdom, Rep. 126, Inst. of Hydrol., Wallingford, U. K.

Bouma, J. (1990), Using morphometric expressions for macropores to improve soil physical analyses of field soils, Geoderma, 46, 3-13.

Bouma, J. (1992), Effect of soil structure, tillage and aggregation upon soil hydraulic properties, in Interacting Processes in Soil Science, edited by R. S. Wagenet, P. Baveye, and B. A. Stewart, pp. 1-37, Lewis, Boca Raton, Fla.

Bouma, J. (2001a), The role of soil science in the land negotiation process, Soil Use Manage., 17, 1-6.

Bouma, J. (2001b), The new role of soil science in a network society, Soil Sci., 166, 874-879.

Bouma, J. (2003), The role of research when implementing European environmental legislation at the national level, Neth. J. Agric. Sci., 50, $267-275$.

Bouma, J. (2005), Soil scientists in a changing world, Adv. Agron., 88, 67-96.

Bouma, J. (2006), Hydropedology as a powerful tool to environmental policy research, Geoderma, 131, 275-286.

Bouma, J., A. Jongerius, and D. Schoonderbeek (1979), Calculation of the saturated hydraulic conductivity of some pedal clay soils using micromorphometric data, Soil Sci. Soc. Am. J., 43, 261-264.

Bouma, J., B. J. van Alphen, and J. J. Stoorvogel (2002), Fine tuning water quality regulations in agriculture to soil differences, Environ. Sci. Policy, $5,113-120$. 
Breeuwsma, A., J. H. M. Wösten, J. J. Vleeshouwer, A. M. van Slobbe, and J. Bouma (1986), Derivation of land qualities to assess environmental problems from soil surveys, Soil Sci. Soc. Am. J., 50, 186-190.

Buol, S. W., R. J. Southard, R. C. Graham, and P. A. McDaniel (2001), Soil Genesis and Classification, 5th ed., Iowa State Univ. Press, Ames.

Cook, S. E., R. J. Corner, G. Grealish, P. E. Gessler, and C. J. Chartes (1996), A rule-based system to map soil properties, Soil Sci. Soc. Am. J., 60, 1893-1900.

Crawford, J. W., Y. A. Pachepsky, and W. J. Rawls (1999), Integrating processes in soils using fractal models, Geoderma, 88, 103-109.

Cushman, J. H. (1990), An introduction to hierarchical porous media, in Dynamics of Fluids in Hierarchical Porous Media, edited by J. H. Cushman, pp. 1-6, Elsevier, New York.

Dijkerman, J. C. (1974), Pedology as a science: The role of data, models and theories in the study of natural soil systems, Geoderma, 11, 73-93.

Droogers, P., and J. Bouma (1997), Soil survey input in exploratory modeling of sustainable soil management practices, Soil Sci. Soc. Am. J., 61, 1704-1710.

Dunn, S. M., and A. Lilly (2001), Investigating the relationship between a soils classification and the spatial parameters of a conceptual catchmentscale hydrological model, J. Hydrol., 252, 157-173.

European Confederation of Soil Science Societies (2004), Scientific Basis for the Management of European Soil Resources: Research Agenda, Guthman-Peterson, Vienna.

Faybishenko, B. A., G. S. Bodvarsson, J. Hinds, and P. A. Witherspoon (2003), Scaling and hierarchy of models for flow processes in unsaturated fractured rock, in Scaling Methods in Soil Physics, Y. A. Pachepsky, D. E. Radcliffe, and H. M. Selim, pp. 373-417, CRC Press, Boca Raton, Fla.

Ferrier, R. C., and A. C. Edwards (2002), Sustainability of Scottish water quality in the early 21st century, Sci. Total Environ., 294, 57-71.

Gerke, H. H., and M. T. van Genuchten (1996), Macroscopic representation of structural geometry for simulating water and solute movement in dualporosity media, Adv. Water. Resour., 19, 343-357.

Grayson, R., and G. Blöschl (Eds.) (2000), Spatial Pattern in Catchment Hydrology: Observations and Modeling, Cambridge Univ. Press, New York.

Grayson, R. B., A. W. Western, F. H. S. Chiew, and G. Blöschl (1997), Preferred states in spatial soil moisture patterns: Local and non-local controls, Water Resour. Res., 33, 2897-2908.

Grayson, R., G. Blöschl, A. W. Western, and T. A. McMahon (2002), Advances in the use of observed spatial patterns of catchment hydrological response, Adv. Water Res., 25, 1313-1334.

Grossman, R. B., D. S. Harms, C. A. Seybold, and J. E. Herrick (2001), Coupling use-dependent and use-invariant data for soil quality evaluation in the United States, J. Soil Water Conserv., 56, 63-68.

Haigh, M. J. (1987), The holon: Hierarchy theory and landscape research, Catena, 10, 181-192.

Heuvelink, G. B. M., and R. Webster (2001), Modelling soil variation: Past, present, and future, Geoderma, 100, 269-301.

Hollenbeck, K. J., T. J. Schmugge, G. M. Hornberger, and J. R. Wang (1996), Identifying soil hydraulic heterogeneity by detection of relative change in passive microwave remote sensing observations, Water Resour. Res., 32, 139-148.

Hoosbeek, M. R., and R. B. Bryant (1992), Towards the quantitative modeling of pedogenesis - A review, Geoderma, 55, 183-210.

Hoosbeek, M. R., H. M. van Es, and A. Stein (Eds.) (1998), Special issue: Modeling spatial and temporal variability as a function of scale, Geoderma, $85,111-254$.

Hornberger, G. M., J. P. Raffensperger, P. L. Wiberg, and K. N. Eshleman (1998), Elements of Physical Hydrology, Johns Hopkins Univ. Press, Baltimore, Md

Hudson, B. D. (1992), The soil survey as paradigm-based science, Soil Sci. Soc. Am. J., 56, 836-841.

Hunt, A. (2005), Percolation Theory for Flow in Porous Media, Springer, New York.

Jackson, T. J., and D. E. Le Vine (1996), Mapping surface soil moisture using an aircraft-based passive instrument: Algorithm and example, J. Hydrol., 18, 85-99.

Jenny, H. (1941), Factors of Soil Formation: A System of Quantitative Pedology, McGraw-Hill, New York.

Jury, W. A. (1999), Present directions and future research in vadose zone hydrology, in Vadose Zone Hydrology: Cutting Across Disciplines, edited by M. B. Parlange and J. W. Hopmans, pp. 433-441, Oxford University Press, New York.

Kachanoski, R. G., and E. de Jong (1988), Scale dependence and the temporal persistence of spatial patterns of soil water storage, Water Resour. Res., 24, 85-91.
Kalma, J. D., and M. Sivapalan (Eds.) (1995), Scale Issues in Hydrological Modelling, John Wiley, Hoboken, N. J.

Lilly, A., and H. S. Lin (2004), Using soil morphological attributes and soil structure in pedotransfer functions, in Development of Pedotransfer Functions in Soil Hydrology, edited by Y. Pachepsky and W. Rawls, pp. 115-142, Elsevier, New York.

Lilly, A., D. B. Boorman, and J. M. Hollis (1998), The development of a hydrological classification of UK soils and the inherent scale changes, Nutr. Cycl. Agroecosyst., 50, 299-302.

Lin, H. S. (2003), Hydropedology: Bridging disciplines, scales, and data, Vadose Zone J., 5, 317-340.

Lin, H. S. (2005), Letter to the Editor on "From the Earth's critical zone to Mars exploration: Can soil science enter its golden age?", Soil Sci. Soc. Am. J., 69, $1351-1353$.

Lin, H. S. (2006), Temporal stability of soil moisture spatial pattern and subsurface preferential flow pathways in the Shale Hills Catchment, Vadose Zone J., 5, 317-340.

Lin, H. S., and S. Rathbun (2003), Hierarchical frameworks for multiscale bridging in hydropedology, in Scaling Methods in Soil Physics, edited by Y. Pachepsky, D. Radcliffe, and H. M. Selim, pp. 353-371, CRC Press, Boca Raton, Fla.

Lin, H. S., J. Bouma, L. Wilding, J. Richardson, M. Kutilek, and D. Nielsen (2005a), Advances in hydropedology, Adv. Agron., 85, 1-89.

Lin, H. S., D. Wheeler, J. Bell, and L. Wilding (2005b), Assessment of soil spatial variability at multiple scales, Ecol. Modell., 182, 271-290.

Lin, H. S., W. Kogelmann, C. Walker, and M. A. Bruns (2006), Soil moisture patterns in a forested catchment: A hydropedological perspective, Geoderma, 131, 345-368.

Maidment, D. (Ed.) (2002), Arc Hydro: GIS for Water Resources, ESRI, Redlands, Calif.

McBratney, A. B., I. O. A. Odeh, T. F. A. Bishop, M. S. Dunbar, and T. M. Shatar (2000), An overview of pedometric techniques for use in soil survey, Geoderma, 97, 293-327.

McBratney, A. B., M. L. Mendonca Santos, and B. Minasny (2003), On digital soil mapping, Geoderma, 117, 3-52.

McKenzie, N. J., and P. J. Ryan (1999), Spatial prediction of soil properties using environmental correlation, Geoderma, 89, 67-94.

McSweeney, K., P. E. Gessler, B. Slater, R. D. Hammer, J. C. Bell, and G. W. Petersen (1994), Towards a new framework for modeling the soillandscape continuum, in Factors of Soil Formation: A Fiftieth Anniversary Retrospective, edited by R. G. Amundson et al., Spec. Publ. Soil Sci. Soc. Am., 33, 127-145.

Mohanty, B. P., and T. H. Skaggs (2001), Spatio-temporal evolution and timestable characteristics of soil moisture within remote sensing footprints with varying soil, slope, and vegetation, Adv. Water Resour., 24, 1051-1067.

National Research Council (NRC) (1991), Opportunities in the Hydrologic Sciences, Natl. Acad. Press, Washington, D. C.

National Research Council (NRC) (1999), New Strategies for America's Watersheds, Natl. Acad. Press, Washington, D. C.

National Research Council (NRC) (2001a), Basic Research Opportunities in Earth Science, Natl. Acad. Press, Washington, D. C.

National Research Council (NRC) (2001b), Conceptual Models of Flow and Transport in the Vadose Zone, Natl. Acad. Press, Washington, D. C.

Oades, J. M., and A. G. Waters (1991), Aggregate hierarchy in soils, Aust. J. Soil Res., 29, 815-828.

O’Neill, R. V., D. L. DeAngelis, J. B. Waide, and T. F. H. Allen (1986), A Hierarchical Concept of Ecosystems, Monogr. Popul. Biol., vol. 23, Princeton Univ. Press, Princeton, N. J.

O’Neill, R. V., A. R. Johnson, and A. W. King (1989), A hierarchical framework for the analysis of scale, Landscape Ecol., 3, 193-205.

Pachepsky, Y. A., and W. R. Rawls (Eds.) (2004), Development of Pedotransfer Functions in Soil Hydrology, Elsevier, New York.

Pachepsky, Y. A., D. E. Radcliffe, and H. M. Selim (Eds.) (2003), Scaling Methods in Soil Physics, CRC Press, Boca Raton, Fla.

Pachepsky, Y. A., K. Smettem, J. Vanderborght, M. Herbst, and H. Vereecken (2004), Reality and fiction of models and data in soil hydrology, in Unsaturated Zone Modeling: Progress, Applications and Challenges, edited by R. A. Feddes and G. de Rooj, pp. 233-260, Springer, New York.

Panday, S., and P. S. Huyakorn (2004), A fully coupled physically-based spatially-distributed model for evaluating surface/subsurface, Adv. Water Resour., 27, 361-382.

Park, S. J., and P. L. G. Vlek (2002), Environmental correlation of threedimensional soil spatial variability: A comparison of three adaptive techniques, Geoderma, 109, 117-140.

Pulleman, M. M., J. Bouma, E. A. van Essen, and E. W. Meijles (2000), Soil organic matter content as a function of different land use history, Soil Sci. Soc. Am. J., 64, 689-694. 
Quisenberry, V. L., B. R. Smith, R. E. Philips, H. D. Scott, and S. Nortcliff (1993), A soil classification system for describing water and chemical transport, Soil Sci., 156, 306-315.

Rawls, W. J., and Y. A. Pachepsky (2002), Soil consistence and structure as predictors of water retention, Soil Sci. Soc. Am. J., 66, 1115-1126.

Reed, P. M., et al. (2006), Bridging river basin scales and processes to assess human-climate impacts and the terrestrial hydrologic system, Water Resour. Res., doi:10.1029/2005WR004153, in press.

Simonson, R. W. (1959), Outline of a generalized theory of soil genesis, Soil Sci. Soc. Am. Proc., 23, 152-156.

Šimunek, J., N. J. Jarvis, M. T. van Genuchten, and A. Gardenas (2003), Review and comparison of models for describing non-equilibrium and preferential flow and transport in the vadose zone, J. Hydrol., 272, 14-35.

Soil Survey Division Staff (1993), Soil Survey Manual, Agric. Handb., vol. 18, U.S. Gov. Print. Off., Washington, D. C.

Sommer, M., M. Wehrhan, M. Zipprich, U. Weller, W. Zu Castell, S. Ehrich, B. Tandler, and T. Selige (2003), Hierarchical data fusion for mapping soil units at field scale, Geoderma, 112, 179-196.

Sonneveld, M. P. W., J. Bouma, and A. Veldkamp (2002), Refining soil survey information for a Dutch soil series using land use history, Soil Use Manage., 18, 157-163.

Sposito, G. (Ed.) (1998), Scale Dependence and Scale Invariance in Hydrology, 423 pp., Cambridge Univ. Press, New York.

Sposito, G., and R. J. Reginato (Eds.) (1992), Opportunities in Basic Soil Science Research, Soil Sci. Soc. of Am., Madison, Wis.

Tisdall, J. M., and J. M. Oades (1982), Organic matter and water-stable aggregates in soils, J. Soil Sci., 33, 141-163.

Vachaud, G., A. De Silans Passerat, P. Balabanis, and M. Vauclin (1985), Temporal stability of spatially measured soil water probability density function, Soil Sci. Soc. Am. J., 49, 822-827.

VanderKwaak, J. E., and K. Loague (2001), Hydrologic-response simulations for the R-5 catchment with a comprehensive physics-based model, Water Resour. Res., 37, 999-1013.

van Genuchten, M. T., and J. Šimunek (2004), Integrated modeling of vadose zone flow and transport processes, in Unsaturated Zone Modeling: Progress, Applications and Challenges, edited by R. A. Feddes and G. de Rooj, pp. 37-69, Springer, New York.

Vogel, H. J., and K. Roth (2003), Moving through scales of flow and transport in soil, J. Hydrol., 272, 95-106.

Vogel, H. J., I. Cousin, and K. Roth (2002), Quantification of pore structure and gas diffusion as a function of scale, Eur. J. Soil Sci., 53, 465-473.

Wagenet, R. J. (1998), Scale issues in agroecological research chains, Nutr. Cycl. Agroecosyst., 50, 23-34.

Western, A. W., and R. B. Grayson (2000), Soil moisture and runoff processes at Tarrawarra, in Spatial Patterns in Catchment Hydrology: Observations and Modelling, edited by R. B. Grayson and G. Blöschl, pp. 209-246, Cambridge Univ. Press, New York.
Western, A. W., R. B. Grayson, and G. Blöschl (2002), Scaling of soil moisture: A hydrologic perspective, Annu. Rev. Earth Planet. Sci., 205, $20-37$.

Wilding, L. P. (2000), Pedology, in Handbook of Soil Science, edited by M. E. Sumner, pp. E-1-E-4, CRC Press, Boca Raton, Fla.

Wilding, L. P., and H. S. Lin (2006), Advancing the frontiers of soil science towards a geoscience, Geoderma, 131, 257-274.

Winter, T. C. (2001), The concept of hydrologic landscapes, J. Am. Water Resour. Assoc., 37, 335-349.

Wood, E. F. (1999), The role of lateral flow: Over- or underrated, in Integrating Hydrology, Ecosystem Dynamics, and Biogeochemistry in Complex Landscapes, edited by J. D. Tenhunen and P. Kabat, pp. 197215, John Wiley, Hoboken, N. J.

Wösten, J. H. M., J. Bouma, and G. H. Stoffelsen (1985), The use of soil survey data for regional soil water simulation models, Soil Sci. Soc. Am. J., 49, 1238-1245.

Yeh, T.-C., and J. Šimunek (2002), Stochastic fusion of information for characterizing and monitoring the vadose zone, Vadose Zone J., 1, 207221.

Zhang, T., and R. Berndtsson (1991), Analysis of soil water dynamics in time and space by use of pattern recognition, Water Resour. Res., 27, $1623-1636$

Zhu, A. X., B. Hudson, J. Burt, K. Lubich, and D. Simonson (2001), Soil mapping using GIS, expert knowledge, and fuzzy logic, Soil Sci. Soc. Am. J., 65, $1463-1472$.

J. Bouma, Soil Science Centre, Wageningen University and Research Centre, P.O. Box 47, 6700 AA Wageningen, Netherlands.

A. Lilly, Macaulay Land Use Research Institute, Craigiebuckler AB15 8QH, UK.

H. Lin, Department of Crop and Soil Sciences, Pennsylvania State University, University Park, PA 16802, USA. (henrylin@psu.edu)

Y. Pachepsky, Environmental Microbial Safety Laboratory, ARS, USDA, Building 173-BARC-East, Powder Mill Road, Beltsville, MD 20705, USA.

J. Thompson, Division of Plant and Soil Sciences, West Virginia University, Morgantown, WV 26506, USA.

R. van Genuchten, George E. Brown Jr. Salinity Laboratory, ARS, USDA, 450 West Big Springs Road, Riverside, CA 92507, USA.

H.-J. Vogel, Department Soil Physics, Center for Environmental Research, Theodor-Lieser-Straße 4, D-06120 Halle, Germany.

A. Western, Department of Civil and Environmental Engineering, University of Melbourne, Parkville, Vic 3052, Australia. 


\section{University Library}

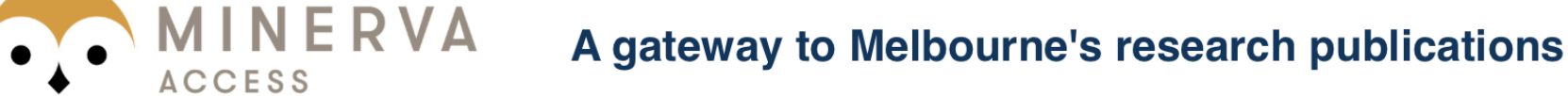

Minerva Access is the Institutional Repository of The University of Melbourne

Author/s:

Lin, H;Bouma, J;Pachepsky, Y;Western, A;Thompson, J;van Genuchten, R;Vogel, H-J;Lilly, A

Title:

Hydropedology: Synergistic integration of pedology and hydrology

Date:

2006-05-09

Citation:

Lin, H., Bouma, J., Pachepsky, Y., Western, A., Thompson, J., van Genuchten, R., Vogel, H. -J. \& Lilly, A. (2006). Hydropedology: Synergistic integration of pedology and hydrology. Water Resources Research, 42 (5), https://doi.org/10.1029/2005WR004085.

Persistent Link:

http://hdl.handle.net/11343/297413 